\title{
Adipose-derived stem cell therapies for bone regeneration
}

\section{Marta Barba, Giuseppe Di Di Taranto \& Wanda Lattanzi}

To cite this article: Marta Barba, Giuseppe Di Di Taranto \& Wanda Lattanzi (2017): Adiposederived stem cell therapies for bone regeneration, Expert Opinion on Biological Therapy, DOI: 10.1080/14712598.2017.1315403

To link to this article: http://dx.doi.org/10.1080/14712598.2017.1315403

Accepted author version posted online: 04 Apr 2017.

Submit your article to this journal ¿

View related articles $₫$

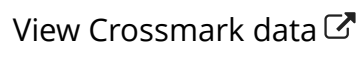


Publisher: Taylor \& Francis

Journal: Expert Opinion on Biological Therapy

DOI: $10.1080 / 14712598.2017 .1315403$

\section{Adipose-derived stem cell therapies for bone regeneration}

Marta Barba ${ }^{1 *}$, Giuseppe Di Taranto ${ }^{2 *}$, Wanda Lattanzi ${ }^{1 \S}$.

1. Institute of Anatomy and Cell Biology, Università Cattolica del Sacro Cuore, Rome, Italy;

2. Department of Plastic, Reconstructive and Aesthetic Surgery, University of Rome "Sapienza", Policlinico Umberto I, Rome, Italy

* MB and GdT contributed equally

$\S$ Please address correspondence to:

Wanda Lattanzi

Institute of Anatomy and Cell Biology

Università Cattolica del Sacro Cuore

Largo F. Vito, 1

00168 Rome, Italy

wanda.lattanzi@unicatt.it

\section{ABSTRACT}

Introduction: Cell-based therapies exploit the heterogeneous and self-sufficient biological environment of stem cells to restore, maintain and improve tissue functions. Adipose-derived stem cells (ASCs) are, to this aim, promising cell types thanks to advantageous isolation procedures, growth kinetics, plasticity and trophic properties. Specifically, bone regeneration represents a suitable, though often challenging, target setting to test and apply ASC-based therapeutic strategies.

Areas covered: ASCs are extremely plastic and secrete bioactive peptides that mediate paracrine functions, mediating their trophic actions in vivo. Numerous preclinical studies demonstrated that ASCs improve bone healing. Clinical trials are ongoing to validate the clinical feasibility of these approaches. This review is intended to define the state-of-the-art on ASCs, encompassing the biological features that make them suitable for bone regenerative strategies, and to provide an update on existing preclinical and clinical applications.

Expert opinion: ASCs offer numerous advantages over other stem cells in terms of feasibility of clinical translation. Data obtained from in vivo experimentation are encouraging, and clinical trials are ongoing. 
More robust validations are thus expected to be achieved during the next few years, and will likely pave the way to optimized patient-tailored treatments for bone regeneration.

KEYWORDS: Adipose tissue, Adipose-derived stem cells, ASCs, regenerative medicine, bone regeneration. 


\section{Introduction}

Therapeutic strategies aimed at regenerating bone have undergone a significant boost during the last two decades, providing a paradigm shift in reconstructive surgery, which significantly improved clinical outcomes. Bone regeneration is needed in skeletal reconstruction of large bone defects resulting from trauma, infections, tumor resection and skeletal abnormalities, or whenever the regenerative process is compromised [1].

The best effective, clinically available, therapeutic options for skeletal reconstruction are currently restricted to autologous and allogeneic bone grafts, along with synthetic bone substitutes[2-6]. The main disadvantage of bone autografts resides in the morbidity of the donor site, where a skeletal defect is created, especially in the presence of overall poor clinical conditions, along with the limited source availability [6]. Furthermore, the complexity of autograft procedures raises other technical issues in selected skeletal sites [7].The use of allogenic bone is inherently associated with morbidities deriving from residual immune-related and infectious burden, along with reduced cost-effectiveness. Finally, synthetic bone substitutes often lack sufficient osteoinductive and osteogenic properties, while providing not always optimal osteoconduction, resorption times and biomechanical assets, especially for the treatment of large skeletal defects [8].

Indeed, the limited success of auto- and allografts in some clinical situations has stimulated the scientific research to investigate new therapeutic tools, possibly tailored to adapt to specific indications and patients' needs. On this regard, somatic stem cell-based approaches are widely considered the best effective, as they enable sustaining the physiologic osteogenic process in vivo and may provide effective osteoinductive stimuli [9].

Bone marrow stromal cells (BMSCs) have been widely exploited in this context, as they represent the physiological precursors for the osteoblastic cell lineage [10-12]. Nonetheless, the limited amount and stem cell yield, along with the invasive harvesting procedure, hamper a wide exploitation of bone marrow as a clinically available cell therapeutics source and have prompted the identification and characterization of additional MSC niches, located within alternative tissue sources.

To date, MSC-like multipotent stem cells have been isolated from a multitude of adult tissues, including muscle, adipose tissue, connective tissue, trabecular bone and periosteum [12], skull sutures [13], synovial fluid [14], along with perinatal tissues [15; 16]. More recently, the advent of induced pluripotent stem cells (iPSCs), obtained through genetic engineering of somatic cells, and possessing high proliferation and differentiation capabilities, has offered additional promising alternative sources for bone regeneration [17; 18]. In many cases, iPSCs have been demonstrated to exert comparable osteogenic capabilities to those displayed by MSCs [19]. Nonetheless, the possibility of reprogramming the genetic background of host 
somatic cells used for iPSCs' production, may offer to unique chance to address the challenge of treating congenital skeletal disorders due to germline mutations [20;21].

In particular, tissue sources that may be collected as "waste" tissues resulting from either surgical interventions (e.g. adipose tissue from lipoaspiration or abdominoplasty),or delivery (i.e. amniotic fluid, term umbilical cord and placenta) offer a significant translational advantages, as they would allow overcoming a number of concerns related with local morbidity, safety, and ethical issues.

In particular, the placenta and related perinatal tissues represent a high-yield reservoir of mesenchymallike multipotent stem cells, endowed with increased stemness potential, and displaying extended plasticity towards multiple lineages [16]. The osteogenic properties of these cells have been demonstrated in vitro [22-23]. Also, a number of preclinical studies have supported the application of these cell-based therapies for the regeneration of musculoskeletal tissues [24]. Moreover, the reproducible ability of these cells to engraft at the site of inflammation and injury, and to modulate the immune/inflammatory response in host tissues, have prompted their potential application in degenerative and immune-based conditions that may affect the musculoskeletal system [25-27].

Among the adult postnatal tissue sources of MSCs, the adipose tissue (AT), given its ubiquity, the ease of retrieval, and the minimally invasive procedure required for harvesting, may be reasonably regarded as an attractive source of multipotent somatic stem cells, namely, adipose-derived stem cells (ASCs) [28]. ASCs reside in the stromal vascular fraction (SVF) of AT, from which they are easily isolated through enzymatic digestion and plastic adherence. They display BMSC-like features, including immunophenotype, trilineage potential and gene expression profile [29-31]. In vitro and in vivo models suggest that the transplantation of expanded ASCs improves bone healing through direct differentiation into mature osteoblasts and paracrine effects that facilitate migration and differentiation of resident precursors. Indeed, ASCs demonstrated relevant trophic properties that suggest the suitability for cell therapy applications: angiogenicity [30; 3234], osteogenicity [30; 35], immunomodulation [36], and promotion of tissue remodeling [34; 37-39].

This review is, indeed, intended to focus on AT as a valuable reservoir of somatic stem cells, specifically considering the state-of-the-art on the osteogenic potential of ASCs. To this aim, we will rely on a careful and up-to-date revision of the extant scientific literature, reporting the characterization of ASCs' biological properties along with the functional validation of their capability to induce bone regeneration and healing in preclinical studies. Finally, we will report on the clinical trials that have exploited these cells for human bone regenerative applications.

\section{AT as a source of somatic stem cells: adipose-derived stem cells (ASCs)}


For a long time AT has been considered exclusively as an energy reservoir, hence usually discarded with surgical waste after liposuction. During the last three decades, numerous research efforts have been put forth towards recognizing AT as an endocrine organ, which controls metabolism, immunity and satiety. Thereafter, a significant breakthrough was made in 2001, when AT was originally described as an attractive new source of adult stem cells (namely, adipose-derived stem cells, ASCs) [28].

AT is a highly complex tissue comprising mature adipocytes (>90\%) and a stromal vascular fraction (SVF), which includes preadipocytes, fibroblasts, vascular smooth muscle cells, endothelial cells, resident monocytes/macrophages, lymphocytes, and ASCs [40-42]. The density of the AT stem cell reservoir varies as a function of type of age, histotype (white or brown AT) and anatomical location (subcutaneous or visceral adipose tissue) [43-49].

Within the white fat, subcutaneous depots house a higher number of ASCS compared with visceral fat. The highest concentrations typically found in the arm region and the greatest plasticity described in cells isolated from inguinal AT [50]. Also, our research group have recently characterized the differential biological properties between the two AT layers separated by the superficial fascia in selected regions of the body, and found a higher cell viability and stemness properties in the superficial compared with the deep hypoderm [51]. Noticeably, adherent cells isolated superficial hypodermal AT showed a higher plasticity, including osteogenic potential, in vitro [51]. An independent study had previously reported a gender-related difference affecting the osteogenic differentiation rates in ASCs, derived from superficialversus-deep subcutaneous AT [52].

Also, Lee and colleagues had characterized the ASCs isolated from different abdominal fat depots on the basis of the regional distribution. This study highlighted that ASCs isolated from superficial subcutaneous depots have a higher grow rate and angiogenic capability, confirming this AT layer as the most appropriate source for therapeutic fat grafting [53].

Human ASCs are usually isolated from subcutaneous AT collected through liposuction or during reconstructive surgery, through resection of tissue fragments. Standard isolation procedures imply the fractionation of AT and separation of the SVF through centrifugation, and further collagenase disruption [54]. One of the main challenges for an adequate translation of AT- and SVF-based therapeutics to the clinical setting, is the generation of a clinical grade protocol of isolation, based on minimal tissue manipulation. On this regard, a wide variety of medical devices enabling the automatic processing of AT for SVF separation and ASC isolation, are being rapidly introduced in the marketplace, sometimes without prior adequate preclinical testing and validation [55-58]

Upon SVF isolation and homogenization, ASCs are selected in vitro based on their plastic adherence properties, and display the typical spindle-shaped fibroblastoid morphology. They can be extensively 
subcultivated in monolayer culture, and rapidly expanded, with a basal growth medium containing $10 \%$ of fetal bovine serum $[31 ; 59 ; 60]$.

ASCs meet most of the minimal criteria set by the International Society for Cellular Therapy (ISCT) to define human mesenchymal stem cells (MSCs) [61]: plastic-adherence, in vitro trilineage (osteogenic, chondrogenic, and adipogenic) potential, expression of the MSC-specific antigens CD73, CD90, and CD105, and lack of hematopoietic lineage markers [61].

Nonetheless, their correct immunophenotype characterization has been long debated. Based on the hematopoietic marker CD45, the endothelial marker CD31, the perivascular marker CD146, and the stromal markers CD34, CD90, CD105 and CD117 (c-kit), four distinct populations have been defined in the SVF fraction (in uncultured conditions): putative ASCs (CD31-, CD34+/-, CD45-, CD90+, CD105-, CD117- and CD146-), endothelial-progenitor cells (CD31+, CD34+, CD45-, CD90+, CD105-, CD117+ and CD146+), vascular smooth muscle cells or pericytes (CD31-, CD34+/-, CD45-, CD90+, CD105-, CD117+ and CD146+), and hematopoietic cells $(C D 45+)$ [54; 62]. Studies on whole AT have revealed that within the stem/progenitor components, organized around small vessels, stromal multipotent cells with CD34+, CD31-, CD104-, SMA,immunophenotype are prevalent in the supra-adventitial layer [62-64]. Pericytes and other cells defined bythe differential expression of CD34, CD31, and CD146 were sorted from the SVF of human white AT. Besides pericytes, CD34+ CD31- CD146- CD45- cells, which reside in the outmost layer of blood vessels (i.e. tunica adventitia), natively express MSC markers and give rise to clonogenic multipotent progenitors, in culture, identical to BMSCs [46; 65]. Finally, studies from Cinti's group have identified a small subset of capillary endothelial cells that are plausibly capable to give rise to adipose lineage cells too $[65 ; 66]$.

The average frequency of ASCs in processed lipoaspirate is $2 \%$ of nucleated cells, and the yield is approximately 5,000 fibroblast colony-forming units (CFU-F) per gram of AT. In the bone marrow, the yield of BMSCs is approximately 100-1,000 CFU-F per milliliter [67], suggesting that AT could be a best efficient source of multipotent stromal stem cells.

Recently, the fluid portion separated by centrifugation of liposucted AT (i.e. lipoaspirate fluid, LAF) contains an ASC-like population (LAF cells) suspended in blood/saline fluid, along with tissue fractions and cell secretome $(40 ; 68)$. LAF cells display the same biological features as ASCs, hence could be reasonably exploited for regenerative applications $(40 ; 55 ; 69)$.

\section{Osteoinductive properties of ASCs}

The secretome of ASCs contains different pro-angiogenic and endocrine factors (adipokines) with bone inducing activity [70]. The expression of these factors can be modulated by different culture conditions, such as proliferation, differentiation and hypoxia. In particular, low oxygen levels in culture inhibit the 
expression of ECM remodeling proteins, such as osteonectin, collagen type 1 , collagen type 2, fibronectin 1 and TGF- $\beta 1$-induced protein, while 3D culture activates the expression of several genes involved in ECM structure and related functions i.e. HGF, VEGF, KGF, b-FGF, MMP-2, and MMP-14 [44]. Interestingly, Kalinina and colleagues highlighted a specific immunophenotype (CD90+/CD73+/CD105+/CD45-/CD31/PDGFR $\beta+/ N G 2+/ C D 146+(-)$ that induces ASCs secretion of ECM proteins (i.e. laminins, fibronectin 1, osteoblast specific factors, osteonectin, periostin, collagens and collagens interacting proteins) [71]. The effects of specific molecules both on the secretome composition and on its pro-osteogenic activity have been largely investigated [72-76]. In particular, the effect of TGF- $\beta 1$ on ASCs' secretome was assessed by Rodriguez and colleagues. The Authors concluded that TGF- $\beta 1$ exposure modulates the expression of several molecules in ASCs, including HGF, leptin, FGF-7 and OPN, involved in bone resorption [77]. Similarly, Overman and colleagues analyzed how osteoinductive treatments, scaffold interaction, and the cell differentiation status, affect the ASCs secretome. This study revealed that BMP2-induced osteogenic differentiation causes the increase of cytokines, such as IL-6, growth factors, such as FGF7, and adhesion molecules, such as VCAM1, in the ASCs' secretome [78]. Moreover, the vascular endothelial growth factor (VEGF), present in the secretome of both whole fresh SVF and isolated ASCs, plays a major role in the repair of fractures or bone defects. VEGF is able to activate the formation of a new network of blood capillaries, which is required during physiological bone formation and healing. In addition, VEGF plays a direct role in the recruitment of hematopoietic stem cells, involved in the formation of new bone [54].

Reasonably, the ASC secretome contribute to the composition of the acellular portion of the lipoaspirate fluid (LAF). We have previously demonstrated that this fluid is able to exert angiogenic and osteoinductive properties in vitro [55]. We have further investigated the proteome-peptidome composition of LAF through a top down/bottom up approach [68]. This study allowed identifying numerous bioactive proteins, peptides and paracrine factors, such as albumin and hemoglobin fragments (i.e. VV- and LVV-hemorphin-7), ubiquitin and acyl-CoA binding protein, adipogenesis regulatory factor, and perilipin-1 fragments. In addition, several molecules directly or indirectly involved in osteogenic process have been reported. In particular, the thymosin beta 4 (T.4) and beta 10 (T.10) peptides, along with their C-terminal-truncated forms, have been identified. These molecules promote angiogenesis, wound healing and tissue repair, in addition to anosteo- inductive activity. The LAF also featuredS100A6, a member of the $\mathrm{S} 100 \mathrm{Ca}^{2+}$-binding protein family. S100A6 induces bone formation modulating the capability of cells to sense extracellular cations [68].The documented presence ASC-like cells and bioactive molecules in the LAF, along with its rapid and easy isolation, make this fluid attractive and suitable for regenerative medicine applications, specifically as a "minimally manipulated tissue" to be tested in vivofor a potentially wide range of applications.

\section{Age-related changes in ASCs' biology and regenerative properties}


An aging population is inevitably going to demand more in terms of regenerative strategies, including those based on fat transfer and grafting. Nonetheless, adipose tissue is not spared by the degenerative processes occurring in elderly. Aging is indeed accompanied by a loss of adipocytes' energy-expending capacity, which may contribute to the development of obesity. In this condition the accumulation of senescent cells, including perivascular stem cells and endothelial cells, along with an increase in circulating proinflammatory cytokines, including TNF $\alpha$ and IL-6, is described [79]. Aging of the adipose tissue niche leads to proliferative defects due to changes in external signals originating in the microenvironment [80]. Several studies demonstrated the effect of age on ASCs' viability and function, in both humans and animal models [79]. In particular, Rogers and colleagues demonstrated that age-related quantitative and functional loss of subcutaneous AT is associated with a selective decline in brown thermogenic adipocytes in mice [81].

Zhu and collaborators demonstrated that ASCs isolated from human liposucted subcutaneous AT display a reduced plasticity (in terms of osteogenic potential), in older compared with younger female donors, regardless of the cellular yield [82]. The gene expression profiles of human senescent subcutaneous AT specimens, also pointed to a significant a decreased ASCs' yield, growth kinetics and differentiation capacities in older donors [83; 84]. In addition, ASCs from older donors display increased oxidative stress markers, coupled with a reduced detoxification capability [85], possibly explaining their impaired proliferation and plasticity [86].

Ye and collaborators compared ASCs isolated from orbital AT of old-versus-young donors, and found fewer progenitor cells, reduced proliferative rates, increased senescent features and decreased trilineage potential, despite no significant differences in overall cellular yield and immunophenotype [87]. Finally, a significant decrease in ASCs' yield and angiogenic capacity, has been demonstrated also in visceral fat depots of elder individuals [88]. Taken together, these data strongly highlight the dramatic effect of aging on ASCs' properties that must be taken into account in the design and development of autologous ATbased regenerative treatments in the elderly.

\section{OSTEOGENIC PROPERTIES: Preclinical studies}

In vitro assays aimed at demonstrating ASCs' multipotency have been widely utilized as part of the standard characterization protocols. These involve the induction with culture medium supplemented appropriate differentiation stimuli, followed by lineage-specific stainings and gene expression profiling [66]. Nonetheless, in order to achieve robust and sound scientific evidence of the functionally effective cell plasticity, in vivo transplantation assays are mandatory [89].

A plethora of studies have been conducted attempting to obtain valid in vivo data demonstrating the osteogenic potential of ASCs and to adequately translate in vitro findings to a clinical level [90]. Several animal models have been designed, employing either allogenic or xenogenic cells transplantation. When employing human ASCs, nude or athymic animals embody a reliable model for studying osteogenic 
processes, as injured bone repair requires the participation of both the immune and hematopoietic niches. Although nude animals demonstrate a blunted inflammatory response, they can still mount an inflammatory B-cells and NK-cells response and possess the surrounding osteogenic precursor cells from the periosteum [90; 91].

The in vivo osteogenic potential of experimental design can be evaluated in an elementary model, relying on local intramuscular injection inducing ectopic bone formation [30; 92-102]. Calvarial defects offer the benefit of studying bone healing in animal models, allowing an easy quantification of the amount of newly formed bone within a bidimensional defect [92; 103-135]. Several models, mostly rodent, have been described to assess calvarial defects and it has been reported that a $4 \mathrm{~mm}$ mouse parietal bone defect is sufficient to offer a reliable and easily repeatable prototype [91]. Long bone skeletal defect models have been widely employed, as they are able to mimic the clinical condition of bone fracture or injury under load bearing stress $[117 ; 136-153]$. In particular, the femur offers special benefits, due to its larger shaft, tolerating a wider defect and allowing the placement of external fixator devices or distracters [136-142; $151 ; 152]$.

The study of ASCs for bone regeneration has largely involved the insertion of biomaterials in rat and nude mouse models. Furthermore, to demonstrate the application and optimization of ASC therapies, these defect models have been also experimented in other different species, achieving successful results. To this aim, either undifferentiated ASC (i.e. in the absence of any prior ex vivo osteogenic induction) or uncultured SVF $[92 ; 100 ; 111]$ have been exploited, paving the way to an easier translation of preclinical evidence to the clinical setting.

Taken together, the numerous studies published so far on this topic, have reported a huge amount of data demonstrating the efficacy of ASC-based approaches for inducing bone regeneration/healing in vivo. Nonetheless, based on the heterogeneity of experimental designs, a direct comparison and systematic account of all studies would be ineffective. Instead, Table 1 reports a tabular view of the most relevant studies designed on this topic, categorizing publications according to the experimental model and species employed, the use of scaffolds or additional treatments, and the origin of graft [22; $23 ; 30 ; 92-159]$.

Growth factors, which are naturally expressed within the healthy bone matrix or during fracture healing, have been explored as promoter of the direct development of the structures of osteogenic tissue and the differentiation of bone cells [160]. The osteoinductive potential of recombinant BMPs has been broadly demonstrated in animal models and clinical studies [90-92; 161]. Since the Food and Drug Administration (FDA) approved the use of recombinant human BMP-2 for spine fusion and granted a device exemption for the use of BMP-7 to treat recalcitrant nonunions, the interest in BMPs increased rapidly as long as the number of published studies [142]. However, the results of both animal and clinical studies have been 
somewhat disappointing and recent evidence has suggested that BMPs, even in combination with ASCs, should not be considered the best viable strategy for inducing bone healing [142]. Furthermore, although high doses of recombinant BMPs induce bone formation, recombinant proteins are expensive, and there are concerns about potential oncogenic effects, considering their pleiotropic functions.

New transcription factors involved in the osteogenic process have been, also, reported, including runtrelated transcription factor 2 (RUNX2), vascular endothelial growth factor (VEGF), LIM mineralization protein (LMP), Sonic Hedgehog (SHH) and Nell-1. Several studies, reviewed by Romagnoli and colleagues [2], demonstrated that the over-expression of these genes significantly increases the osteogenic potential of ASCs.

Finally, the limited success of auto- and allo-bone grafts in some clinical situations has stimulated the investigation of a wide variety of biomaterials to design osteoconductive scaffolds for clinical applications. Well characterized biomaterials, such as hydroxyapatite (HA), beta-tricalcium phosphate ( $\beta$-TCP), biphasic calcium phosphate (BCP), implemented or not with bioactive glasses, have been widely explored in preclinical studies and are currently used in different clinical applications [162; 163]. Taken together, these results demonstrated the potential of bioactive scaffold in bone remodeling, providing an additional effective strategy for treating bone defects. Indeed, in the last years, several in vitro and in vivo studies highlighted the osteo-inductive role of biomimetic scaffolds on ASCs, showing how the use of the biopolimers as substrate to growth could embody a useful trigger for the differentiation of the ASCs toward the osteoblastic phenotype[54; 164-170].

\section{Clinical use of ASCs for bone regeneration/reconstruction}

Despite the numerous successful preclinical applications of ASCs-based therapy for bone regeneration, few clinical trials have been reported, and completed to date. The official international clinical trial database (https://clinicaltrials.gov/, keywords: adipose derived stem cells AND bone) counts 19 studies, 7 of which focusing on ASCS and bone regeneration/reconstruction, excluding those with "unknown status". These include two completed trials and one terminated. Four studies investigated the use of ASCs in bone or composite graft applied to different bone defect models. Two trials were designed to determine whether ASCs injection was effective in severe osteoarthritis. One trial aimed on studying ASCs effect on avascular necrosis of femoral head. However, no result or relevant data have been reported, to date.

Lendeckel and colleagues described the use of autologous ASCs combined with bone graft and fibrin glue to treat a large pediatric post-traumatic calvarial defect in a case report [171]. Three-month follow-up CT scan showed almost complete calvarial healing with a stable osteo-integrated graft. Mesimäki and colleagues 
described a novel method to reconstruct a major maxillary defect in an adult patient using autologous ASCs combined with recombinant human BMP-2 and $\beta$-TCP granules. The patient's healing was clinically uneventful, obtaining new, mature, vital and vascularized bone eight months after surgery, with good osteointegration and stability [172]. Thesleff and colleagues employed ASCs for calvarial reconstruction, testing alternative biomaterials ( $\beta$ TCP and resorbable mesh bilaminate scaffold) and obtaining successful results in adult patients [173]. Sandor and colleagues reported the successful reconstruction of large anterior mandibular bone defects using ASC seeded on a $\beta$ TCP pre-molded scaffold, custom based on patient's' CT scans [174]. The same Authors reviewed a 13 cases series of cranio-maxillofacial hard-tissue defects reconstructed with either bioactive glass or $\beta$ TCP scaffolds seeded with ASCs, reporting successful integration and bone regeneration in 10 cases [175]. Pak and colleagues described the complete resolution of avascular necrosis of the femoral head treated with ASCS and PRP injection [176]. In a clinical trial, Castillo-Cardier and colleagues investigated autologous ASCs application in mandibular angle fractures as an alternative to conventional reduction treatment, evaluating healing time and ossification rate; at 12 weeks follow-up CT scan revealed higher percentage of ossification in the experimental group [177]. Dufrane and colleagues proved the feasibility of a scaffold-free three-dimensional ASCs graft, designed for facing reconstruction of long bone defect in the context of congenital pseudarthrosis or tumor resection [178]. Prins and colleagues evaluated the potential effect of freshly isolated SVF seeded on either $\beta$ TCP or biphasic calcium phosphate carriers in patients undergoing maxillary sinus floor elevation, using a one-step surgical procedure, proving the feasibility, safety and efficacy of the technique, irrespective of the bone substitute [179].

Despite ASCs are being proven to be suitable candidates for tissue reconstruction in several surgical applications, they are still far from being an "off-the-shelf" product, based on the current regulatory issues. The national regulatory agencies (i.e. the Food and Drug Administration in US and the European Medicines Agency in EU) provide the official rules and guidelines that guarantee safe and controlled procedures, requiring Good Manufacturing Practice (GMP) to be fulfilled during cell therapy production and applications [180]. Accordingly, whenever cell culture expansion is required to produce a cell-based treatment to be used in a clinical setting, this is labeled as an "advanced cell therapy". GMP-proof facilities (i.e. cell factories) are mandatorily needed for the entire cell processing procedure, in this case. It is also recommended to use approved GMP-manufactured, or anyway appropriately validated clinical grade reagents. Therefore, given that most applications described in the scientific literature imply extensive ex vivo processing of AT and SVF for ASCs isolation and expansion, these rules should be satisfied to move forward into the clinical setting. Conversely, the procedures involved in the isolation and use of fresh SVF or LAF (not requiring cell culture stages) are classified as minimal tissue processing. This setting does not require classified environments, hence would be closer to clinical translation, based on the existing regulatory issues. 


\section{ASCs-based bone regeneration in geriatric applications}

Nowadays, stem cell therapies should inevitably address the increased medical challenges deriving from the progressive aging of the population (at least in western countries), associated with an inherently increased demand for regenerative applications to treat the structural frailty of older patients. Hence, the design and translation of AT-based experimental regenerative strategies are expected to cope with these issues [181]. In particular, decreased bone mass and mineral density, along with degenerative joint disease, scarcopenia and muscle weakness, are indeed part of the frail phenotype affecting the entire musculoskeletal system in elder people. To date, few, although encouraging, results have been achieved in clinical studies exploiting ASCs for the treatment of typical geriatric conditions, specifically affecting the skeletal system. Pak and colleagues reported the safety and feasibility of percutaneous intraarticular injections of uncultured ASC-containing SVF (associated with platelet-rich plasma) in patients suffering from chronic or degenerative joint disease [182].

Besides the limited data available from clinical trials, several preclinical studies have tested the feasibility and efficacy of ASC-based strategies for the treatment of age-related bone disorders, particularly osteoporosis. To this aim, animal models of ovariectomy-induced osteoporosis have been widely exploited, accounting for a multitude of preclinical reports. A recent metanalysis of preclinical studies in different animal models of osteoporosis attempted to combine this huge amount of data [183] Focusing on ASCs, the results consistently indicate that ASCs-based treatments were able to improve bone mineral density and reduce bone loss in different osteoporotic animal models [183-185].In addition, local injection of ASCs infected with lentiviral vectors expressing human alpha-1 antitrypsin protein improved bone-morphometric parameters and succeeded in partially reversing the ovariectomy-induced bone loss [186].

Furthermore as regenerative stem-cell therapies are almost entirely based on an autologous approaches, it is reasonable to consider whether osteoporosis could influence the biological properties of ASCs, when harvested from osteopenic patients. Indeed, the cell regenerative capacity and osteogenic potential of ASCs, isolated from the inguinal subcutaneous AT were found impaired in osteoporotic mice [187]. Similarly, ASCS from ovariectomized rats exhibited a comparable proliferation capacity compared with controls, but showed relatively lower osteogenic potential in a critical-size calvarial defect model [188].

Another study demonstrated that the recovery of osteoporosis achieved by ASCs transplantation, tended to decrease with donor age in osteoporotic mice [185].

While the aforementioned studies reported results of local ASCs transplantations, anew regenerative therapy for the prevention of bone loss, employing the systemic administration of aspirin and allogeneic ASCs, was tested in an ovariectomized mice model and demonstrated temporary recovery of bone loss [189]. 
These data collectively provide promising clues towards the design and development of advanced ASCbased stem cell therapies for the treatment of age-associated bone frailty and osteoporosis. Nonetheless, further testing in the clinical setting need to be implemented, and patient-tailored approaches should be defined in order to cope with the several co-morbidities affecting an aged patient.

\section{Concluding remarks}

During the last decades the scientific literature agreed to indicate ASCs as a new promising tool to be exploited in bone regenerative applications. Current regulatory issues in matter of "bioprocess engineering products" encouraged the development of closed devices for the isolation of ASCs/SVF, enabling minimal tissue manipulation. Preliminary outcomes of clinical studies are confirming the results obtained in animal models, suggesting that either native or cultured ASCs, alone or in combination with biomimetic scaffolds and/or treatments, are able to improve bone healing. Taken together, these data highlight the growing translational relevance of the use of ASCs for bone repair.

\section{Expert opinion}

Since the original description, 15 years ago, of adipose-derived stem cells (ASCs), research on these cells has become a cutting-edge topic in the field of regenerative medicine, with over 8500 papers published in PubMed, to date. Our research group, interested in bone biology and genetics, started focusing on ASCs with the aim of identifying a suitable cell source, alternative to BMSCs, to be exploited in experimental biological therapies aimed at regenerating bone.

For the reasons detailed in this review, ASCs potentially offer a number of advantages over adult stem cells from other sources (such as bone marrow, amniotic membrane, etc), in terms of feasibility of clinical translation. In particular, not only adipose tissue is found basically in all individuals, with extended availability and relatively easy harvesting, but it also yields high amounts of viable stem cells, compared with other tissue sources. The recently achieved standardization of nomenclature and isolation protocols, along with the improved characterization of stem cell niches, is rapidly leading to the development of safer and more targeted autologous transplantation protocols, with optimized patient-tailored prioritization of harvesting sites.

Besides their multipotency and trophic features, ASCs display immune-modulatory and paracrine effects exerted through their secretome, similarly to mesenchymal stromal cells isolated from other tissue sources. These features enlarge significantly the ground of actual and potential applications of ASC-based therapies. 
Despite the limited comparability of the outcomes obtained through in vivo transplantation assays, the exploitation of ASCs in bone regenerative strategies has evolved at the same pace as their in vitro and ex vivo biological characterization. Even though the adipogenic niche is distinct from the skeletogenic niche, by proper definition, a number of biological similarities suggest a reciprocal ex/interchange between these two systems. Indeed, adipose tissue is found in spatial proximity with both angiogenic and osteogenic precursors within a bone segment, and represents a closely interacting domain, with bi-directional plasticity. ASCs indeed indirectly contribute to the homeostasis of bone development, remodeling and healing, in vivo, mostly due to the secretion of bioactive molecules exerting paracrine effects on the osteogenic lineage. Several preclinical studies, and selected clinical trials, to date, have confirmed that ASCs represent suitable cell therapies for regenerating large bone defects, whenever endogenous BMSCs are not sufficient, and/or transplanted BMSC are not feasible, to sustain osteogenesis. In most cases, in order to achieve successful bone healing, the designed strategies involve genetic engineering and/or ex vivo osteoinductive priming of ASCs, prior to in vivo implantation (see details on preclinical studies and clinical trials in this review). Nonetheless, distinct studies reported the capability of undifferentiated native ASCs to drive the osteogenic process in vivo. This capability is reasonably the result of a fruitful combination of their demonstrated plasticity and their bioactive peptide-enriched secretome, enabling the delivery of trophic paracrine effects at the site where new bone synthesis is required.

Despite the already existing evidence, it is likely and highly desirable that, in the next years, uncontroversial information would derive from improved and reproducible preclinical studies, from the successful completion of clinical trials, and from the implementation of optimal osteoconductive scaffolds. Altogether, these scientific facts will enable confirming that ASCs-based treatments could regenerate a fully functional bone tissue, with a correct structural architecture and efficient integration, at least in selected skeletal sites. Lastly, new challenges are being offered to the biomedical research community, by the progressive aging of the Western world population, along with the rapid development of genomic technologies that allow defining patient-specific backgrounds. These factors are delineating a rapidly changing medical scenario, in which targeted cell-based therapies will need to be as precise as possible, and personalized to cope with specific demands of wellbeing and improved performance, from the aging population.

\section{Funding:}

The authors are funded by the Università Cattolica del Sacro Cuore, Linea D.1 - 2017. M Barba and W Lattanzi are also funded by National Institutes of Health $(\mathrm{NIH})$ and National Institutes of Dental and Craniofacial Research (NIDCR) grant 2 R01-DE016886-06 while W Lattanzi also has receive grant support from the Ministero della Salute - Ricerca Finalizzata GR-2011-02348622. 


\section{Declaration of Interest:}

The authors have no relevant affiliations or financial involvement with any organization or entity with a financial interest in or financial conflict with the subject matter or materials discussed in the manuscript. This includes employment, consultancies, honoraria, stock ownership or options, expert testimony, grants or patents received or pending, or royalties.

\section{ARTICLE HIGHLIGHTS BOX:}

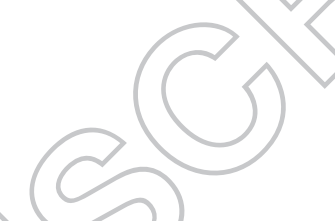

Adipose tissue houses multipotent somatic stem cells (aka adipose-derived stem cells, ASCs) residing in perivascular niches.

Significant advancements in ASCs' research have been achieved in the last decades, leading to improved knowledge of their biology and potentialities.

- $\quad$ ASCs exert osteoinductive properties, by secreting bioactive molecules and growth factors that mediate their paracrine trophic effects.

ASCs are extremely plastic and proved to be capable of inducing bone regeneration in distinct animals models.

- Strict regulatory issues are to be met in order to achieve a safe and efficient clinical translation of the numerous experimental data on ASC-based therapies.

- Clinical trials are ongoing to provide the final confirmation of the correct and feasible exploitation of ASCs for the treatment of bone defects and of disorders characterized by impaired endogenous osteogenesis and bone remodeling. 
Table 1. Preclinical studies on ASC osteoregenerative potential.

\begin{tabular}{|c|c|c|c|c|c|}
\hline Experimental model & Species & Scaffold / administration & Additionalex vivo/in vivo treatment & Grafttype & Reference \\
\hline Calvarialdefect & Rat & PLGA & Alendronate & Xenogeneic & 103 \\
\hline Calvarialdefect & Rabbit & HA-PLGA, collagensponge & BV-BMP2/ TGF $\beta 3$ & Allogeneic & 104 \\
\hline Calvarialdefect & Mouse & PLGA & Dura mater & Xenogeneic & 105 \\
\hline Calvarialdefect & Rat & $\beta-\mathrm{TCP}$ & Lenti-miR-31 & Allogeneic & 106 \\
\hline Calvarialdefect & Mouse & Custom scaffold & NOGGIN shRNA-Knockout & Xenogeneic & 30 \\
\hline Calvarialdefect & Dog & HA-PLGA & None & Xenogeneic & 108 \\
\hline Calvarialdefect & Mouse & Systemicinjection & None & Allo/xenogeneic & 109 \\
\hline Calvarialdefect & Mouse & Local injection & None & Xenogeneic & 110 \\
\hline Calvarialdefect* & Rat & DBM, PLA & None & Xenogeneic & 111 \\
\hline Calvarialdefect & Rat & MAP-coated PCL/PLGA & None & Xenogeneic & 112 \\
\hline Calvarialdefect & Rat & HA- $\beta$-TCP & None & Xenogeneic & 113 \\
\hline Calvarialdefect & Rat & PLGA & None / ostegenic medium & Xenogeneic & 114 \\
\hline Calvarialdefect & Dog & Coral & Osteogenicinduction & Autologous & 115 \\
\hline Calvarialdefect & Dog & Coral & Osteogenicinduction & Allogeneic & 95 \\
\hline Calvarialdefect & Pig & Collagen sponge & Osteogenic induction & Autologous & 116 \\
\hline Calvarialdefect* & Rat & DBX & Osteogenic induction & Allogeneic & 117 \\
\hline Calvarialdefect & Rat & PCL-PLGA- $\beta$-TCP & Osteogenic induction + HUVEC & Xenogeneic & 118 \\
\hline Calvarialdefect & Mouse & pDA-PLGA & rhBMP-2 & Xenogeneic & 119 \\
\hline Calvarialdefect & Rabbit & Collagensponge & rhBMP-2 & Allogeneic & 120 \\
\hline Calvarialdefect & Mouse & HA-PLGA & Sonic hedgehog signaling Induction & Xenogeneic & 121 \\
\hline Calvarialdefect & Rat & Local injection & VEGFa & Xenogeneic & 122 \\
\hline Calvarialdefect & Rat & Local injection & PRP & Allogenic & 123 \\
\hline Calvarialdefect & Rabbit & Fibronectin-treated PLA/PLA & None / Osteogenic induction & Allogenic & 124 \\
\hline Calvarialdefect & Rat & PLA & None/ Osteogenic induction / endothelial induction/ coculture & Allogenic & 125 \\
\hline Calvarialdefect & Rabbit & TCP/BAG $/>$ & BMP-2/ BMP-7/ VEGF & Autologous & 126 \\
\hline Calvarialdefect & Rat & Bio-Oss + Collagen type I & None & Xenogeneic & 127 \\
\hline Calvarialdefect & Dog & $P C L+\beta$-TCP/ASCs-sheet+PCL+ $\beta$-TCP & None / Osteogenic induction & Autologous & 128 \\
\hline Calvarialdefect & Rabbit & $\mathrm{BAG} / \mathrm{TCP}$ & Iron-labeling & Autologous & 129 \\
\hline Cavarialdefect & Rabbit & Polyamide/PLGA/DAM & Osteogenic induction & Autologous & 130 \\
\hline Calvarialdefect & Mouse $>$ & PLGA & BMP-2/miR-148b baculovirus vectors & Xenogenic & 131 \\
\hline Calvarialdefect & Rat $/ A$ & $\mathrm{CH}+\mathrm{HA}$ & $17 \beta$-Estradiol & Allogenic & 132 \\
\hline Calvarialdefect & Mouse & Decellularizedtendon & Osteogenic induction & Xenogenic & 133 \\
\hline Calvarialdefect & Mouse $>$ & PLGA & None & Autologous & 133 \\
\hline Calvarialdefect & Rat $\triangle$ & BAG & None & Autologous & 134 \\
\hline Calvarialdefect & Mouse & SPCL & None & Autologous & 135 \\
\hline Ectopic bone formation/ Calvarial defect* & Mouse/Rat & $\mathrm{HC}$ & None & Xenogenic & 92 \\
\hline Ectopic bone formation & Mouse & PLGA & BMP2/RUNX2 bicistronic vector & Xenogeneic & 93 \\
\hline Ectopic bone formation & Mouse & PRP + alginate microsphere & None & Allogeneic & 94 \\
\hline
\end{tabular}




\begin{tabular}{|c|c|c|c|c|c|}
\hline Ectopic bone formation & Mouse & $\beta$-TCP & None & Xenogeneic & 95 \\
\hline Ectopic bone formation & Rat & $\mathrm{HA}$ & None & Xenogeneic & 96 \\
\hline Ectopic bone formation & Rat & Matrigel & Osteogenicinduction & Xenogeneic & 97 \\
\hline Ectopic bone formation & Rat & DBM & Osteogenicinduction & Xenogeneic & 30 \\
\hline Ectopic bone formation & Mouse & Carbon nanotubes & rhBMP2 & Xenogeneic & 99 \\
\hline Ectopic bone formation & Rat & PLDA & rhBMP2 & Xenogeneic & 100 \\
\hline Ectopic bone formation* & Mouse & $\mathrm{BMM}+\mathrm{PRP}$ & None & Allegenic & 101 \\
\hline Ectopic bone formation & Mouse & $\beta-\mathrm{TCP}$ & Chondrogenicinduction / None & Xenogenic & 102 \\
\hline Ectopic bone formation & Mouse & polyurethane + spheroids & None / Osteogenic induction & Allogenic & 103 \\
\hline Femurdefect & Mouse & Systemicinjection & None & Allogeneic & 136 \\
\hline Femurdefect & Rat & Fibrinmatrix & rhBMP2 & Allogeneic & 137 \\
\hline Femurdefect & Rat & $\beta-\mathrm{TCP}$ & Lenti-BMP2/7 & Allogeneic & 138 \\
\hline Femur defect & Rat & Collagen gel & None & Xenogeneic & 139 \\
\hline Femurdefect & Rabbit & PLGA & BMP2 and VEGF baculovirus vectors & Autologous & 140 \\
\hline Femurdefect & Sheep & Titanium & Osteogenic induction / serum deprivation & Autologous & 141 \\
\hline Femurdefect & Rat & Collagen-ceramic & BMP-2-carrying adenovirus & Xenogenic & 142 \\
\hline Femurdefect + distractor & Rat & Type I collagen gel & None & Allogenic & 143 \\
\hline Ulna defect & Rabbit & PLGA & None / osteogenic medium & Xenogeneic & 117 \\
\hline Ulna defect & Rabbit & DBM & None / Osteogenic induction & Allogenic & 124 \\
\hline Radialdefect & Dog & $\beta-\mathrm{TCP}$ & None & Allogeneic & 144 \\
\hline Radialdefect & Rabbit & PLA/PCL + vascularizedperiosteum & Ad-Cbfa1 & Allogeneic & 136 \\
\hline Radial defect & Rabbits & HA-PLA-COL & Ad-hBMP2 & Allogeneic & 145 \\
\hline Tibia defect & Rabbit & $\mathrm{HA}$ & None & Autologous & 146 \\
\hline Tibia defect + distractor & Rabbit & Local injection & None & Autologous & 147 \\
\hline Tibia defect & Rabbit & $\mathrm{HA}$ & None & Autologous & 148 \\
\hline Tibia defect & Dog & PRP & None & Xenogeneic & 149 \\
\hline Tibia defect & Mouse & Injection & None & Autologous & 150 \\
\hline Femurosteochondraldefect & Rabbit & Local injection & Bovine BMP & Allogeneic & 151 \\
\hline Femurosteochondraldefect & Rabbit & Ceramics, biphasicmaterials & none & allogeneic & 152 \\
\hline Spinal fusion & Mouse & Local injection & rhBMP6 nucleofection & Xenogeneic & 170 \\
\hline Spinal fusion & Rat & Lyophilized human cancellous bone & Gal-KO + osteogenicinduction & Xenogeneic & 169 \\
\hline Spinal fusion/ Femurdefect & Pig & $3 D-D B M$ & DBM + Osteogenic induction & Autologous & 129 \\
\hline Vertebraldefect & Rat & Fibrin gel & rhBMP6 nucleofection & Xenogeneic & 171 \\
\hline Mandibledefect & PIg & Local-systemicinjection & None & Allogeneic & 174 \\
\hline Mandibledefect & Rat & $\mathrm{HA} / \mathrm{COL}$ & None & Xenogeneic & 173 \\
\hline Mandibledefect & Rabbit & $\mathrm{CH}+\mathrm{CS}$ & BMP2 + NOGGIN shRNA-Knckout & Xenogenic & 133 \\
\hline Mandibledefect & Pig $A$ & DBM & 3D- Osteogenic induction & Autologous & 147 \\
\hline Alveolardefect & Rat & PLGA & None & Allogenic & 146 \\
\hline
\end{tabular}

Alveolardefect

PLGA

None

matrix; $\beta$-TCP : beta-tricalcium phosphate; Lenti-miR-31: lentivirus expression vector carrying the microRNA-31; p-DA: polydopamine; PRP: platelet-rich plasma; Lenti-BMP2/7: lentivirus

expression vector carrying either the BMP2 or the BMP7 gene, MAP: mussel adhesive proteins, NOGGIN shRNA : short hairpin ribonucleic acid to knockdown NOGGIN gene, COL: collagen; BAG:

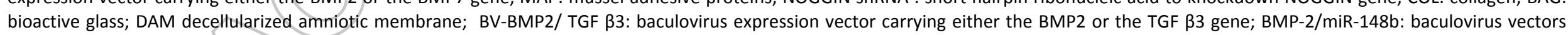


carrying the microRNA-148b and BMP2 genes; CH: Chitosan; CS: chondroitin sulfate; Gal-KP: galactosyl-knock-out; a-CaP: amorphous calcium phosphate; 3D-DBM: three-dimentional demineralized bone matrix. BMM: bone mineral matrix. SPCL: starch-polycaprolactone. HC: Engineered and devitalized hypertrophic cartilage. *: these studies were based on uncultured SVF instead of culture-amplified ASCs. 


\section{REFERENCES}

1. Romagnoli C, Brandi ML. Adipose mesenchymal stem cells in the field of bone tissue engineering. World J Stem Cells. 2014;6(2):144-152. doi: 10.4252/wjsc.v6.i2.144.

2. Zhang $G$, Brion $A$, Willemin $A S$, et al. Nacre, a natural, multi-use, and timely biomaterial for bone graft substitution. J Biomed Mater Res A. 2017;105(2):662-671. doi: 10.1002/jbm.a.35939.

3. Fillingham $Y$, Jacobs J. Bone grafts and their substitutes. Bone Joint J. 2016;98-B(1 Suppl A):6-9. doi: 10.1302/0301-620X.98B.36350.

4. Emara KM, Diab RA, Emara A. Recent biological trends in management of fracture non-union. World J Orthop. 2015;6(8):623-8. doi: 10.5312/wjo.v6.i8.623.

5. Campana V, Milano G, Pagano $E$, et al., Bone substitutes in orthopaedic surgery: from basic science to clinical practice. J Mater Sci Mater Med. 2014;25(10):2445-61. doi: 10.1007/s10856-014-5240-2.

6. Barba $M$, Cicione $C$, Bernardini $C$, et al. Spinal fusion in the next generation: gene and cell therapy approaches. ScientificWorldJournal. 2014;2014:406159. doi: 10.1155/2014/406159.

7. Parrilla $C$, Lattanzi W, Rita FA, et al. Ex vivo gene therapy using autologous dermal fibroblasts expressing hLMP3 for rat mandibular bone regeneration. Head Neck. 2010;32:310-318.

8. Calori GM, Mazza E, Colombo M, et al., The use of bone-graft substitutes in large bone defects: any specific needs? Injury. 2011;42 Suppl 2:S56-63. doi: 10.1016/j.injury.2011.06.011.

9. Bueno EM, Glowacki J. Cell-free and cell-based approaches for bone regeneration. Nat Rev Rheumatol. 2009 Dec;5(12):685-97. doi: 10.1038/nrrheum.2009.228.

10. Zuk PA, Zhu M, Ashjian P, et al. Human adipose tissue is a source of multipotent stem cells. Mol Biol Cell. 2002;13(12):4279-4295.

** This is the original pioneer paper describing adipose-derived stem cells and their properties.

11. Desiderio V, De Francesco F, Schiraldi C, et al. Human Ng2+ adipose stem cells loaded in vivo on a new crosslinked hyaluronic acid-Lys scaffold fabricate a skeletal muscle tissue. J Cell Physiol. 2013;228(8):1762-1773. doi: 10.1002/jcp.24336.

12. Lattanzi W, Parolisi R, Barba M, et al. Osteogenic and Neurogenic Stem Cells in Their Own Place: Unraveling Differences and Similarities Between Niches. Front Cell Neurosci. 2015;9:455. doi: 10.3389/fncel.2015.00455

13. Lattanzi W, Barba $M$, Novegno $F$, et al. Lim mineralization protein is involved in the premature calvarial ossification in sporadic craniosynostoses. Bone. 2013;52:474-484.12.

14. Vériter S, Gianello $P$, Igarashi $Y$, et al. Improvement of subcutaneous bioartificial pancreas vascularization and function by coencapsulation of pig islets and mesenchymal stem cells in primates. Cell Transplant. 2014;23(11):1349-1364. doi: 10.3727/096368913X663550.

15. De CP, Bartsch G Jr, Siddiqui MM, et al. Isolation of amniotic stem cell lines with potential for therapy. Nat Biotechnol. 2007;25:100-106.

16. Fierabracci A, Lazzari L, Muraca M, et al. How far are we from the clinical use of placental-derived mesenchymal stem cells? Expert Opin Biol Ther. 2015;15(5):613-7. doi: 10.1517/14712598.2015.1000856.

17. Lou X. Induced Pluripotent Stem Cells as a new Strategy for Osteogenesis and Bone Regeneration. Stem Cell Rev. 2015;11(4):645-51. doi:10.1007/s12015-015-9594-8.

18. Wu Q, Yang B, Hu K, et al. Deriving Osteogenic Cells from Induced Pluripotent Stem Cells for Bone Tissue Engineering. Tissue Eng Part B Rev. 2017;23(1):1-8. doi: 10.1089/ten.TEB.2015.0559.

19. Bastami F, Nazeman $P$, Moslemi $H$, et al. Induced pluripotent stem cells as a new getaway for bone tissue engineering: A systematic review. Cell Prolif. 2017;50(2). doi: 10.1111/cpr.12321 
20. Barruet E, Hsiao EC. Using Human Induced Pluripotent Stem Cells to Model Skeletal Diseases. Methods Mol Biol. 2016;1353:101-18. doi: 10.1007/7651_2014_171.

21. Hamazaki T, El Rouby N, Fredette NC, et al. Concise Review: Induced Pluripotent Stem Cell Research in the Era of Precision Medicine. Stem Cells. 2017;35(3):545-550. doi: 10.1002/stem.2570

22. Longo UG, Loppini $M$, Berton $A$, et al. Stem cells from umbilical cord and placenta for musculoskeletal tissue engineering. Curr Stem Cell Res Ther. 2012,7: 272-281.

23. Barba $M$, Pirozzi $F$, Saulnier $N$, et al. Lim mineralization protein 3 induces the osteogeníc differentiation of human amniotic fluid stromal cells through Kruppel-like factor-4 downregulation and further bone-specific gene expression. J Biomed Biotechnol. 2012;2012:813894. doi: $10.1155 / 2012 / 813894$.

24. Klontzas ME, Kenanidis El, Heliotis $\mathrm{M}$, et al. Bone and cartilage regeneration with the use of umbilical cord mesenchymal stem cells. Expert Opin Biol Ther. 2015;15(11):1541-52. doi: 10.1517/14712598.2015.1068755

25. Magatti M, De Munari S, Vertua E, et al. Human amnion mesenchyme harbors cells with allogeneic T-cell suppression and stimulation capabilities. Stem Cells. 2008;26(1):182-92

26. Loukogeorgakis SP, De Coppi P. Amniotic fluid stem cells: the known, the unknown and potential regenerative medicine applications. Stem Cells. 2016. doi: 10.1002/stem.2553

27. Pianta S, Magatti M, Vertua E, et al. Amniotic mesenchymal cells from pre-eclamptic placentae maintain immunomodulatory features as healthy controls. J Cell Mol Med. 2016;20(1):157-69. doi: $10.1111 / \mathrm{jcmm} .12715$.

28. Zuk PA, Zhu M, Mizuno $\mathrm{H}$, et al. Multilineage cells from human adipose tissue: implications for cellbased therapies. Tissue Eng. 2001;7(2):211-228.

29. Kern S, Eichler $\mathrm{H}$, Stoeve J, et al. Comparative analysis of mesenchymal stem cells from bone marrow, umbilical cord blood, or adipose tissue. Stem Cells Dayt Ohio. 2006;24 (5):1294-1301.

30. Schubert $T$, Xhema $D$, Vériter $S$, et al. The enhanced performance of bone allografts using osteogenic-differentiated adipose-derived mesenchymal stem cells. Biomaterials. 2011;32(34):8880-8891. doi: 10.1016/j.biomaterials.2011.08.009.

31. Saulnier N, Puglisi MA, Lattanzi W, et al. Gene profiling of bone marrow- and adipose tissue-derived stromal cells: a key role of Kruppel-like factor 4 in cell fate regulation. Cytotherapy. 2011;13:329340.

* this study by our group provided the original characterization of differential properties between bone marrow-and adipose tissue-derived mesenchymal stem cells, and allowed identifying the molecular features underlying their stemness properties.

32. De Francesco F, Tirino V, Desiderio V, et al. Human CD34/CD90 ASCs are capable of growing as sphere clusters, producing high levels of VEGF and forming capillaries. PloS One. 2009;4(8):e6537. doi: 10,1371/journal.pone.0006537.

33. Vériter S, Aouassar N, Adnet P-Y, et al. The impact of hyperglycemia and the presence of encapsulated islets on oxygenation within a bioartificial pancreas in the presence of mesenchymal stem cells in a diabetic Wistar rat model. Biomaterials. 2011;32 (26):5945-5956. doi: 10.1016/j.biomaterials.2011.02.061.

34. Lafosse A, Desmet C, Aouassar N, et al. Autologous adipose stromal cells seeded on a human collagen matrix for dermal regeneration in chronic wounds: clinical proof of concept. Plast Reconstr Surg. 2015;136(2):279-295. doi: 10.1097/PRS.0000000000001437.

35. Schubert T, Lafont $S$, Beaurin $G$, et al. Critical size bone defect reconstruction by an autologous 3D osteogenic-like tissue derived from differentiated adipose MSCs. Biomaterials. 2013a;34(18):44284438. doi: 10.1016/j.biomaterials.2013.02.053. 
36. Schubert T, Poilvache H, Galli C, et al. Galactosyl-knock-out engineered pig as a xenogenic donor source of adipose MSCs for bone regeneration. Biomaterials. 2013b;34(13):3279-3289. doi: 10.1016/j.biomaterials.2013.01.057.

37. Ferraro GA, De Francesco F, Nicoletti G, et al. Human adipose CD34+ CD90+ stem cells and collagen scaffold constructs grafted in vivo fabricate loose connective and adipose tissues. J Cell Biochem. 2013;114(5):1039-1049. doi: 10.1002/jcb.24443.

* this study demonstrate a clinically relevant approach for soft tissue reconstruction based on ASCS and bioactive scaffolds.

38. Tsuji W, Rubin JP, Marra KG. Adipose-derived stem cells: Implications in tissue regeneration. World J Stem Cells. 2014;6(3):312-321. doi: 10.4252/wjsc.v6.i3.312.

39. Vériter S, André W, Aouassar N, et al. Human Adipose-Derived Mesenchymal Stem Cells in Cell Therapy: Safety and Feasibility in Different "Hospital Exemption" Clinical Applications. PLoS One. 2015;10(10):e0139566. doi: 10.1371/journal.pone.0139566.

* this is an informative review useful to categorize the clinical applications of ASCs performed to date.

40. Yoshimura K, Suga H, Eto H. Adipose-derived stem/progenitor cells: roles in adipose tissue remodeling and potential use for soft tissue augmentation. Regen Med. 2009;4:265-273.

41. Weisberg SP, McCann D, Desai M, et al. Obesity is associated with macrophage accumulation in adipose tissue. J Clin Invest. 2003;112:1796-1808.

42. Xu H, Barnes GT, Yang Q, et al. Chronic inflammation in fat plays a crucial role in the development of obesity-related insulin resistance. J Clin Invest. 2003;112:1821-1830.

43. Schipper BM, Marra KG, Zhang W, et al. Regional anatomic and age effects on cell function of human adipose-derived stem cells. Ann Plast Surg. 2008;60:538-544.

44. Levi B, James AW, Glotzbach JP, et al. Depot-specific variation in the osteogenic and adipogenic potential of human adipose derived stromal cells. Plast Reconstr Surg. 2010;126:822-834.

* this study documents the differential biological properties of ASCs from different anatomical sites, hence providing useful data for the clinical prioritization of harvesting sites.

45. Gentile P, Scioli MG, Bielli A, et al. Concise Review: The Use of Adipose-Derived Stromal Vascular Fraction Cells and Platelet Rich Plasma in Regenerative Plastic Surgery. Stem Cells. 2016. doi: 10.1002/stem.2498.

* this study provides the original description of ASCs application feasible in plastic surgery.

46. Guercio A, Di BS, Casella S, et al. Canine mesenchymal stem cells (MSCs): characterization in relation to donor age and adipose tissue-harvesting site. Cell Biol Int. 2013;37: 789-798.

47. Requicha $\mathrm{JF}$, Viegas $\mathrm{CA}$, Albuquerque $\mathrm{CM}$, et al. Effect of anatomical origin and cell passage number on the stemness and osteogenic differentiation potential of canine adipose-derived stem cells. Stem Cell Rev. 2012;8:1211-1222.

48. von Eyben FE, Kroustrup JP, Larsen JF, et al. Comparison of gene expression in intra-abdominal and subcutaneous fat: a study of men with morbid obesity and nonobese men using microarray and proteomics. Ann N Y Acad Sci. 2004;1030:508-536.

49. Grove KL, Fried SK, Greenberg AS, et al. A microarray analysis of sexual dimorphism of adipose tissues in high-fat-diet-induced obese mice. Int J Obes (Lond). 2010;34: 989-1000.

50. Prunet-Marcassus $B$, Cousin B, Caton D, et al. From heterogeneity to plasticity in adipose tissues: site-specific differences. Exp Cell Res. 2006;312:727-736.

51. Di Taranto G, Cicione C, Visconti G, et al. Qualitative and quantitative differences of adiposederived stromal cells from superficial and deep subcutaneous lipoaspirates: a matter of fat. Cytotherapy. 2015;17(8):1076-1089. doi: 10.1016/j.jcyt.2015.04.004. 
* this study documents the differential biological properties of ASCs from different anatomical sites, hence providing useful data for the clinical prioritization of harvesting sites.

52. Aksu AE, Rubin JP, Dudas JR, et al. Role of gender and anatomical region on induction of osteogenic differentiation of human adipose-derived stem cells. Ann Plast Surg. 2008;60:306e22.

53. Lee NE, Kim SJ, Yang SJ, et al. Comparative characterization of mesenchymal stromal cells from multiple abdominal adipose tissues and enrichment of angiogenic ability via CD146 molecule. Cytotherapy. 2016;S1465-3249(16)30581-3. doi: 10.1016/j.jcyt.2016.11.002.

54. Barba M, Cicione C, Bernardini C, et al. Adipose-derived mesenchymal cells for bone regeneration: state of the art. Biomed Res Int. 2013;2013:416391. doi: 10.1155/2013/416391.

55. Cicione C, Di Taranto G, Barba M, et al. In Vitro Validation of a Closed Device Enabling the Purification of the Fluid Portion of Liposuction Aspirates. Plast Reconstr Surg. 2016;137(4):11571167. doi: $10.1097 /$ PRS.0000000000002014.

56. Aronowitz JA, Lockhart RA, Hakakian CS. Mechanical versus enzymatic isolation of stromal vascular fraction cells from adipose tissue. Springerplus. 2015;4:713. doi: 10.1186/s40064-015-1509-2.59.

57. Oberbauer E, Steffenhagen C, Wurzer C, et al. Enzymatic and non-enzymatic isolation systems for adipose tissue-derived cells: current state of the art. Cell Regen (Lond). 2015;4:7. doi: 10.1186/s13619-015-0020-0.E

58. SundarRaj S, Deshmukh A, Priya N, et al. Development of a System and Method for Automated Isolation of Stromal Vascular Fraction from Adipose Tissue Lipoaspirate. Stem Cells Int. 2015;2015:109353. doi: 10.1155/2015/109353.

59. Saulnier N, Lattanzi W, Puglisi MA, et al. Mesenchymal stromal cells multipotency and plasticity: induction toward the hepatic lineage. Eur Rev Med Pharmacol Sci. 2009;13 Suppl 1:71-78.

60. Sterodimas A, de FJ, Nicaretta B, et al. Tissue engineering with adipose-derived stem cells (ADSCs): current and future applications. J Plast Reconstr Aesthet Surg. 2010;63:1886-1892.

61. Dominici M, Le BK, Mueller I, et al. Minimal criteria for defining multipotent mesenchymal stromal cells. The International Society for Cellular Therapy position statement. Cytotherapy 2006;8:315317.

** this study reports the gold standard for definition, characterization, classification and correct nomenclature of mesenchymal stem cells.

62. Zimmerlin L, Donnenberg VS, Pfeifer ME, et al. Stromal vascular progenitors in adult human adipose tissue. Cytometry A. 2010;77:22-30.

63. Lin K, Matsubara Y, Masuda Y, et al. Characterization of adipose tissue-derived cells isolated with the Celution system. Cytotherapy. 2008;10:417-426.

64. Corselli M, Chen CW, Sun B, et al. The tunica adventitia of human arteries and veins as a source of mesenchymal stem cells. Stem Cells Dev. 2012;21: 1299-1308.

65. Tran KV, Gealekman O, Frontini A, et al. The vascular endothelium of the adipose tissue gives rise to both white and brown fat cells. Cell Metab. 2012;15(2):222-229. doi: 10.1016/j.cmet.2012.01.008.

66. Gupta RK, Mepani RJ, Kleiner S, et al. Zfp423 expression identifies committed preadipocytes and localizes to adipose endothelial and perivascular cells. Cell Metab. 2012;15(2):230-239. doi: 10.1016/j.cmet.2012.01.010.

** this study provide original and unique insights into the characterization of the adipose stem cell niche.

67. Bajek A, Gurtowska N, Olkowska J, et al. Adipose-Derived Stem Cells as a Tool in Cell-Based Therapies. Arch Immunol Ther Exp (Warsz). 2016;64(6):443-454. 
68. Inserra I, Martelli C, Cipollina M, et al. Lipoaspirate fluid proteome: A preliminary investigation by LC-MS top-down/bottom-up integrated platform of a high potential biofluid in regenerative medicine. Electrophoresis. 2016;37(7-8):1015-1026. doi: 10.1002/elps.201500504.

69. Francis MP, Sachs PC, Elmore LW, Holt SE. Isolating adipose-derived mesenchymal stem cells from lipoaspirate blood and saline fraction. Organogenesis. 2010;6(1):11-4.

70. Frazier TP, Gimble JM, Kheterpal I, et al. Impact of low oxygen on the secretome of human adiposederived stromal/stem cell primary cultures. Biochimie. 2013;95(12):2286-2296. doi: 10.1016/j.biochi.2013.07.011.

71. Kalinina N, Kharlampieva D, Loguinova $M$, et al. Characterization of secretomes provides evidence for adipose-derived mesenchymal stromal cells subtypes. Stem Cell Res Ther. 2015 Nov 11;6:221. doi: 10.1186/s13287-015-0209-8.

* this study provide crucial hints in the definition of the soluble factors that specify cellular populations and their trophic functions within AT.

72. Gómez-Aristizábal A, Sharma A, Bakooshli MA, et al. Stage-specific differences in secretory profile of mesenchymal stromal cells (MSCS) subjected to early- vs late-stage OA synovial fluid. Osteoarthritis Cartilage. 2016;S1063-4584(16)30413-7. doi: 10.1016/j.joca.2016.11.010.

73. Assoni A, Coatti G, Valadares MC, et al.Different Donors Mesenchymal Stromal Cells Secretomes Reveal Heterogeneous Profile of Relevance for Therapeutic Use. Stem Cells Dev. 2016. doi:10.1089/scd.2016.0218.

74. Riis S, Stensballe A, Emmersen J, et al. Mass spectrometry analysis of adipose-derived stem cells reveals a significant effect of hypoxia on pathways regulating extracellular matrix. Stem Cell Res Ther. 2016;7(1):52. doi: 10.1186/s13287-016-0310-7.

75. Feisst $\mathrm{V}$, Meidinger S, Locke MB. From bench to bedside: use of human adipose-derived stem cells. Stem Cells Cloning. 2015;8:149-162. doi:10.2147/SCCAA.S64373.

76. Bruno S, Deregibus MC, Camussi G. The secretome of mesenchymal stromal cells: Role of extracellular vesicles in immunomodulation. Immunol Lett. 2015;168(2):154-158. doi: 10.1016/j.imlet.2015.06.007.

77. Rodríguez TM, Saldías A, Irigo M, et al. Effect of TGF- $\beta 1$ Stimulation on the Secretome of Human Adipose-Derived Mesenchymal Stromal Cells. Stem Cells Transl Med. 2015;4(8):894-898. doi: 10.5966/sctm.2015-0012.

78. Overman JR, Helder MN, ten Bruggenkate CM, et al. Growth factor gene expression profiles of bone morphogenetic protein-2-treated human adipose stem cells seeded on calcium phosphate scaffolds in vitro. Biochimie. 2013;95(12):2304-2013. doi: 10.1016/j.biochi.2013.08.034.

79. Varghese J, Griffin M, Mosahebi A, et al. Systematic review of patient factors affecting adipose stem cell viability and function: implications for regenerative therapy. Stem Cell Res Ther. 2017;8(1):45. doi: 10.1186/s13287-017-0483-8.

* Important study towards the identification of the clinical variables influencing ASC biology in human donors.

80. Graja A, Schulz TJ. Mechanisms of aging-related impairment of brown adipocyte development and function. Gerontology. 2015;61(3):211-7. doi: 10.1159/000366557.

81. Rogers NH, Landa A, Park S, et al. Aging leads to a programmed loss of brown adipocytes in murine subcutaneous white adipose tissue. Aging Cell. 2012;11(6):1074-83. doi: 10.1111/acel.12010.

82. Zhu M, Kohan E, Bradley J, et al. The effect of age on osteogenic, adipogenic and proliferative potential of female adipose-derived stem cells. J Tissue Eng Regen Med. 2009;3(4):290-301. doi: 10.1002/term.165. 
83. Choudhery MS, Badowski M, Muise A, et al. Donor age negatively impacts adipose tissue-derived mesenchymal stem cell expansion and differentiation. J Transl Med. 2014 Jan 7;12:8. doi: 10.1186/1479-5876-12-8.

84. Alt EU, Senst C, Murthy SN, et al. Aging alters tissue resident mesenchymal stem cell properties. Stem Cell Res. 2012;8(2):215-25. doi: 10.1016/j.scr.2011.11.002.

85. Kornicka K, Marycz K, Tomaszewski KA, et al. The Effect of Age on Osteogenic and Adipogenic Differentiation Potential of Human Adipose Derived Stromal Stem Cells (hASCs) and the Impact of Stress Factors in the Course of the Differentiation Process. Oxid Med Cell Longey. 2015;2015:309169.

86. Marędziak M, Marycz K, Tomaszewski KA, et al. The Influence of Aging on the Regenerative Potential of Human Adipose Derived Mesenchymal StemCells. Stem Cells Int. 2016;2016:2152435.

87. Ye X, Liao C, Liu G, et al. Age-Related Changes in the Regenerative Potential of Adipose-Derived Stem Cells Isolated from the Prominent Fat Pads in Human Lower Eyelids. PLoS One. 2016;11(11):e0166590. doi: 10.1371/journal.pone.0166590.

88. Madonna R, Renna FV, Cellini C, et al. Age-dependent impairment of number and angiogenic potential of adipose tissue-derived progenitor cells. Eur J Clin Invest. 2011;41(2):126-33. doi: 10.1111/j.1365-2362.2010.02384.x.

89. Bianco $P$, Cao $X$, Frenette PS, The meaning, the sense and the significance: translating the science of mesenchymal stem cells into medicine. Nat Med. 2013;19(1):35-42. doi: 10.1038/nm.3028.

** this is a prominent review that clearly states the true translational relevance of mesenchymal stem cells, stressing on their in vitro and in vivo functional features.

90. Gerstenfeld LC, Cullinane DM, Barnes GL, et al. Fracture healing as a post-natal developmental process: molecular, spatial, and temporal aspects of its regulation. J Cell Biochem. 2003; 88:873884.

91. Levi B, Longaker MT. Concise review: adipose-derived stromal cells for skeletal regenerative medicine. Stem Cells. 2011 Apr:29(4):576-82.

92. Todorov A, Kreutz M, Haumer A, et al. Fat-Derived Stromal Vascular Fraction Cells Enhance the Bone-Forming Capacity of Devitalized Engineered Hypertrophic Cartilage Matrix. Stem Cells Transl Med. 2016 Jul 26.

93. Lee SJ, Kang SW, Do HJ, et al. Enhancement of bone regeneration by gene delivery of BMP2/Runx2 bicistronic yector into adipose-derived stromal cells. Biomaterials 2010, 31: 5652-5659.

94. Man Y, Wang P, Guo Y, et al. Angiogenic and osteogenic potential of platelet-rich plasma and adipose-derived stem cell laden alginate microspheres. Biomaterials 2012, 33: 8802-8811.

95. Liu G, Zhang Y, Liu B, et al. Bone regeneration in a canine cranial model using allogeneic adipose derived stem cells and coral scaffold. Biomaterials 2013, 34: 2655-2664.

96. Choi JW, Park EJ, Shin HS, et al. In Vivo Differentiation of undifferentiated Human Adipose TissueDerived Mesenchymal Stem Cells in Critical-Sized Calvarial Bone Defects. Ann Plast Surg 2012.

97. Shen FH, Werner BC, Liang $\mathrm{H}$, et al. Implications of adipose-derived stromal cells in a 3D culture system for osteogenic differentiation: an in vitro and in vivo investigation. Spine J 2013, 13: 32-43.

98. Li X, Liu H, Niu X, et al. The use of carbon nanotubes to induce osteogenic differentiation of human adipose-derived MSCs in vitro and ectopic bone formation in vivo. Biomaterials 2012, 33: 48184827.

99. Chou YF, Zuk PA, Chang TL, et al. Adipose-derived stem cells and BMP2: part 1. BMP2-treated adipose-derived stem cells do not improve repair of segmental femoral defects. Connect Tissue Res 2011, 52: 109-118. 
100. Najman SJ, Cvetković VJ, Najdanović JG, et al. Ectopic osteogenic capacity of freshly isolated adipose-derived stromal vascular fraction cells supported with platelet-rich plasma: A simulation of intraoperative procedure. J Craniomaxillofac Surg. 2016 Aug 24.

101. Brocher J, Janicki P, Voltz P, et al. Inferior ectopic bone formation of mesenchymal stromal cells from adipose tissue compared to bone marrow: rescue by chondrogenic pre-induction. Stem Cell Res. 2013 Nov;11(3):1393-406.

102. Laschke MW, Schank TE, Scheuer C, et al. In vitro osteogenic differentiation of adiposederived mesenchymal stem cell spheroids impairs their in vivo vascularization capacity inside implanted porous polyurethane scaffolds. Acta Biomater. 2014 Oct;10(10):4226-35.

103. Wang $\mathrm{CZ}$, Chen SM, Chen $\mathrm{CH}$, et al. The effect of the local delivery of alendronate on human adipose-derived stem cell-based bone regeneration. Biomaterials 2010, 31: 8674-8683.

104. Lin $\mathrm{CY}$, Chang YH, Li KC, et al. The use of ASCs engineered to express BMP2 or TGF-beta3 within scaffold constructs to promote calvarial bone repair. Biomaterials 2013.

105. Levi B, Nelson ER, Li S, et al. Dura mater stimulates human adipose-derived stromal cells to undergo bone formation in mouse calvarial defects. Stem Cells 2011, 29:1241-1255.

106. Deng $\mathrm{Y}$, Zhou H, Zou D, et al. The role of miR-31-modified adipose tissue-derived stem cells in repairing rat critical-sized calvarial defects. Biomaterials 2013, 34: 6717-6728.

107. Levi B, Hyun JS, Nelson ER, et al. Nonintegrating knockdown and customized scaffold design enhances human adipose-derived stem cells in skeletal repair. Stem Cells 2011, 29: 2018-2029.

108. Lo DD, Hyun JS, Chung MT, et al. Repair of a critical-sized calvarial defect model using adipose-derived stromal cells harvested from lipoaspirate. V Vis Exp 2012.

109. Levi B, James AW, Nelson ER, et al. Studies in adipose-derived stromal cells: migration and participation in repair of cranial injury after systemic injection. Plast Reconstr Surg 2011, 127: 11301140.

110. Levi B, James AW, Nelson ER, et al. Acute skeletal injury is necessary for human adiposederived stromal cell-mediated calvarial regeneration. Plast Reconstr Surg 2011, 127: 1118-1129.

111. Rhee SC, Ji YH, Gharibjanian NA, et al. In vivo evaluation of mixtures of uncultured freshly isolated adipose-derived stem cells and demineralized bone matrix for bone regeneration in a rat critically sized calvarial defect model. Stem Cells Dev 2011, 20: 233-242.

112. Hong JM, Kim BJ, Shim JH, et al. Enhancement of bone regeneration through facile surface functionalization of solid freeform fabrication-based three-dimensional scaffolds using mussel adhesive proteins. Acta Biomater 2012, 8: 2578-2586.

113. So $\mathrm{CH}$, Yoon PW, et al. Comparative evaluation of in vivo osteogenic differentiation of fetal and adult mesenchymal stem cell in rat critical-sized femoral defect model. Cell Tissue Res 2013, 353: 41-52.

114. Yoon E, Dhar S, Chun DE, et al. In vivo osteogenic potential of human adipose-derived stem cells/poly lactide-co-glycolic acid constructs for bone regeneration in a rat critical-sized calvarial defect model. Tissue Eng 2007, 13: 619-627.

115. Cui L, Liu B, Liu G, et al. Repair of cranial bone defects with adipose derived stem cells and coral scaffold in a canine model. Biomaterials 2007, 28: 5477-5486.

116. Stockmann P, Park J, von WC, et al. Guided bone regeneration in pig calvarial bone defects using autologous mesenchymal stem/progenitor cells - a comparison of different tissue sources. J Craniomaxillofac Surg 2012, 40: 310-320.

117. Kim HP, Ji YH, Rhee SC, et al. Enhancement of bone regeneration using osteogenic-induced adipose-derived stem cells combined with demineralized bone matrix in a rat critically-sized calvarial defect model. Curr Stem Cell Res Ther 2012, 7: 165-172. 
118. Kim JY, Jin GZ, Park IS, et al. Evaluation of solid free-form fabrication-based scaffolds seeded with osteoblasts and human umbilical vein endothelial cells for use in vivo osteogenesis. Tissue Eng Part A 2010, 16: 2229-2236.

119. Ko E, Yang K, Shin J, et al. Polydopamine-assisted osteoinductive Peptide immobilization of polymer scaffolds for enhanced bone regeneration by human adipose-derived stem cells. Biomacromolecules 2013, 14: 3202-3213.

120. Smith DM, Cooper GM, Afifi AM, et al. Regenerative surgery in cranioplasty revisited: the role of adipose-derived stem cells and BMP-2. Plast Reconstr Surg 2011, 128: 1053-1060.

121. Levi B, James AW, Nelson ER, et al. Human adipose-derived stromal cells stimulate autogenous skeletal repair via paracrine Hedgehog signaling with calvarial osteoblasts. Stem Cells Dev 2011, 20: 243-257.

122. Behr B, Tang C, Germann G, et al. Locally applied vascular endothelial growth factor A increases the osteogenic healing capacity of human adipose-derived stem cells by promoting osteogenic and endothelial differentiation. Stem Cells 2011, 29: 286-296.

123. Tajima S, Tobita $\mathrm{M}$, Orbay $\mathrm{H}$, et al. Direct and indirect effects of a combination of adiposederived stem cells and platelet-rich plasma on bone regeneration. Tissue Eng Part A. 2015 Mar;21(5-6):895-905.

124. Di Bella C, Farlie P, Penington AJ. Bone regeneration in a rabbit critical-sized skull defect using autologous adipose-derived cells. Tissue Eng Part A. 2008 Apr;14(4):483-90.

125. Shah AR, Cornejo A, Guda T, et al. Differentiated adipose-derived stem cell cocultures for bone regeneration in polymer scaffolds in vivo. J Craniofac Surg. 2014 Jul;25(4):1504-9.

126. Lappalainen OP, Karhula S, Haapea M, et al. Bone healing in rabbit calvarial critical-sized defects filled with stem cells and growth factors combined with granular or solid scaffolds. Childs Nerv Syst. 2016 Apr;32(4):681-8.

127. Daei-Farshbaf N, Ardeshirylajimi A, Seyedjafari E, et al. Bioceramic-collagen scaffolds loaded with human adipose-tissue derived stem cells for bone tissue engineering. Mol Biol Rep. 2014 Feb;41(2):741-9.

128. Kim Y, Lee SH, Kang BJ, et al. Comparison of Osteogenesis between Adipose-Derived Mesenchymal Stem Cells and Their Sheets on Poly- $\varepsilon$-Caprolactone/ $\beta$-Tricalcium Phosphate Composite Scaffolds in Canine Bone Defects. Stem Cells Int. 2016;2016:8414715.

129. Lappalainen OP, Haapea M, Serpi $R$, et al. Iron-labeled adipose stem cells and neovascularization in rabbit calvarial critical-sized defects. Oral Surg Oral Med Oral Pathol Oral Radiol. 2016 May;121(5):e104-10.

130. Cuetković VJ, Najdanović JG, Vukelić-Nikolić MĐ, et al. Osteogenic potential of in vitro osteo-induced adipose-derived mesenchymal stem cells combined with platelet-rich plasma in an ectopic model. Int Orthop. 2015 Nov;39(11):2173-80.

131. Liao $\mathrm{YH}$, Chang $\mathrm{YH}$, Sung $\mathrm{LY}$, et al. Osteogenic differentiation of adipose-derived stem cells and calvarial defect repair using baculovirus-mediated co-expression of BMP-2 and miR-148b. Biomaterials. 2014 Jun;35(18):4901-10.

132. Calis $M$, Demirtas TT, Atilla $P$, et al. Estrogen as a novel agent for induction of adiposederived mesenchymal stem cells for osteogenic differentiation: in vivo bone tissue-engineering study. Plast Reconstr Surg. 2014 Apr;133(4):499e-510e.

133. Ko E, Alberti K, Lee JS, et al. Nanostructured Tendon-Derived Scaffolds for Enhanced Bone Regeneration by Human Adipose-Derived Stem Cells. ACS Appl Mater Interfaces. 2016 Sep 7;8(35):22819-29. 
134. Saçak B, Certel F, Akdeniz ZD, et al. Repair of critical size defects using bioactive glass seeded with adipose-derived mesenchymal stem cells. J Biomed Mater Res B Appl Biomater. 2016 Feb 17.

135. Carvalho PP, Leonor IB, Smith BJ, et al. Undifferentiated human adipose-derived stromal/stem cells loaded onto wet-spun starch-polycaprolactone scaffolds enhance bone regeneration: nude mice calvarial defect in vivo study. J Biomed Mater Res A. 2014 Sep;102(9):3102-11.

136. Lee SW, Padmanabhan P, Ray $P$, et al. Stem cell-mediated accelerated bone healing observed with in vivo molecular and small animal imaging technologies in a model of skeletal injury. J Orthop Res 2009, 27: 295-302.

137. Keibl C, Fugl A, Zanoni G, et al. Human adipose derived stem cells reduce callus volume upon BMP-2 administration in bone regeneration. Injury 2011, 42: 814-820.

138. Qing W, Guang-Xing $C$, Lin $G$ et al. The osteogenic study of tissue engineering bone with BMP2 and BMP7 gene-modified rat adipose-derived stem cell. J Biomed Biotechnol 2012, 2012: 410879.

139. Shoji T, li M, Mifune $\mathrm{Y}$, et al. Local transplantation of human multipotent adipose-derived stem cells accelerates fracture healing via enhanced osteogenesis and angiogenesis. Lab Invest 2010, 90: 637-649.

140. Wallner C, Abraham S, Wagner JM, et al. Local Application of Isogenic Adipose-Derived Stem Cells Restores Bone Healing Capacity in a Type 2 Diabetes Model. Stem Cells Transl Med. 2016 Jun;5(6):836-44.

141. Godoy Zanicotti D, Coates DE, Duncan WJ. In vivo bone regeneration on titanium devices using serum-free grown adipose-derived stem cells, in a sheep femur model. Clin Oral Implants Res. 2016 Feb 8.

142. Peterson B, Zhang J, Iglesias R, et al. Healing of critically sized femoral defects, using genetically modified mesenchymal stem cells from human adipose tissue. Tissue Eng. 2005 JanFeb;11(1-2):120-9.

143. Nomura I, Watanabe K, Matsubara H, et al. Uncultured autogenous adipose-derived regenerative cells promote bone formation during distraction osteogenesis in rats. Clin Orthop Relat Res. 2014 Dec;472(12):3798-806.

144. Kang BJ, Ryu HH, Park SS, et al. Comparing the osteogenic potential of canine mesenchymal stem cells derived from adipose tissues, bone marrow, umbilical cord blood, and Wharton's jelly for treating bone defects. J Vet Sci 2012, 13: 299-310.

145. Hao W, Dong J, Jiang M, et al. Enhanced bone formation in large segmental radial defects by combining adipose-derived stem cells expressing bone morphogenetic protein 2 with nHA/RHLC/PLA scaffold. Int Orthop 2010, 34: 1341-1349.

146. Arrigoni E, Stanco D, Dellavia C, et al. Adipose-derived stem cells and rabbit bone regeneration: histomorphometric, immunohistochemical and mechanical characterization. J Orthop Sci 2013, 18: 331-339.

147. Sunay O, Can G, Cakir Z, et al. Autologous rabbit adipose tissue-derived mesenchymal stromal cells for the treatment of bone injuries with distraction osteogenesis. Cytotherapy. 2013 Jun;15(6):690-702.

148. Arrigoni E, de Girolamo L, Di Giancamillo A et al. Adipose-derived stem cells and rabbit bone regeneration: histomorphometric, immunohistochemical and mechanical characterization. J Orthop Sci. 2013 Mar;18(2):331-9. 
149. Cruz AC, Caon T, Menin Á, et al. Adipose-derived stem cells incorporated into platelet-rich plasma improved bone regeneration and maturation in vivo. Dent Traumatol. 2015 Feb;31(1):42-8.

150. Wallner C, Abraham S, Wagner JM, et al. Local Application of Isogenic Adipose-Derived Stem Cells Restores Bone Healing Capacity in a Type 2 Diabetes Model. Stem Cells Transl Med. 2016 Jun;5(6):836-44.

151. Cao Z, Hou S, Sun D et al. Osteochondral regeneration by a bilayered construct in a cell-free or cell-based approach. Biotechnol Lett 2012, 34: 1151-1157.

152. Fernandez FB, Shenoy S, Suresh BS, et al. Short-term studies using ceramic scaffolds in lapine model for osteochondral defect amelioration. Biomed Mater 2012, 7: 035005.

153. Sheyn D, Pelled G, Zilberman Y, et al. Nonvirally engineered porcine adipose tissue-derived stem cells: use in posterior spinal fusion. Stem Cells 2008, 26: 1056-1064.

154. Sheyn D, Kallai I, Tawackoli W, et al. Gene-modified adult stem cells regenerate vertebral bone defect in a rat model. Mol Pharm 2011, 8: 1592-1601.

155. Wilson SM, Goldwasser MS, Clark SG, et al. Adipose-derived mesenchymal stem cells enhance healing of mandibular defects in the ramus of swine. J Oral Maxillofac Surg 2012, 70: e193e203.

156. Parrilla C, Saulnier N, Bernardini C, et al. Undifferentiated human adipose tissue-derived stromal cells induce mandibular bone healing in rats. Arch Otolaryngol Head Neck Surg 2011, 137: 463-470.

157. Fan J, Park H, Lee MK, et al. Adipose-derived stem cells and BMP-2 delivery in chitosanbased 3D constructs to enhance bone regeneration in a rat mandibular defect model. Tissue Eng Part A. 2014 Aug;20(15-16):2169-79.

158. Bhumiratana S, Bernhard JC, Alfi DM, et al. Tissue-engineered autologous grafts for facial bone reconstruction. Sci Transl Med. 2016 Jun 15;8(343):343ra83.

159. Akita D, Kano K, Saito-Tamura Y, et al. Use of Rat Mature Adipocyte-Derived Dedifferentiated Fat Cells as a Cell Source for Periodontal Tissue Regeneration. Front Physiol. 2016 Feb 23;7:50.

160. Janicki P, Schmidmaier G. What should be the characteristics of the ideal bone graft substitute? Combining scaffolds with growth factors and/or stem cells. Injury. 2011;42 Suppl 2:S7781. doi: 10.1016/j.injury.2011.06.014.

161. Hernandez-Hurtado AA, Borrego-Soto G, Marino-Martinez IA, et al. Implant Composed of Demineralized Bone and Mesenchymal Stem Cells Genetically Modified with AdBMP2/AdBMP7 for the Regeneration of Bone Fractures in Ovis aries. Stem Cells Int. 2016;2016:7403890.

162. Dorozhkin SV. Calcium orthophosphates as bioceramics: state of the art. J Funct Biomater. 2010;1(1):22-107. doi: 10.3390/jfb1010022.

163. van Esterik FA, Zandieh-Doulabi B, Kleverlaan CJ, et al. Enhanced Osteogenic and Vasculogenic Differentiation Potential of Human Adipose Stem Cells on Biphasic Calcium Phosphate Scaffolds in Fibrin Gels. Stem Cells Int. 2016;2016:1934270. doi: 10.1155/2016/1934270.

164. Bellucci D, Sola A, Cannillo V. Hydroxyapatite and tricalcium phosphate composites with bioactive glass as second phase: State of the art and current applications. J Biomed Mater Res A. 2016;104(4):1030-1056. doi: 10.1002/jbm.a.35619.

165. Jones JR. Review of bioactive glass: from Hench to hybrids. Acta Biomater. 2013;9(1):445786. doi: 10.1016/j.actbio.2012.08.023.

166. Varanasi VG, Odatsu T, Bishop T, et al. Enhanced osteoprogenitor elongated collagen fiber matrix formation by bioactive glass ionic silicon dependent on Sp7 (osterix) transcription. J Biomed Mater Res A. 2016;104(10):2604-2615. doi: 10.1002/jbm.a.35795. 
167. Ersoy B, Bayramiçli M, Ercan F, et al. Comparison of bone prefabrication with vascularized periosteal flaps, hydroxyapatite, and bioactive glass in rats. J Reconstr Microsurg. 2015;31(4):291299. doi: 10.1055/s-0034-1396770.

168. Popescu RA, Magyari K, Vulpoi A, et al. Bioactive and biocompatible copper containing glass-ceramics with remarkable antibacterial properties and high cell viability designed for future in vivo trials. Biomater Sci. 2016;4(8):1252-65. doi: 10.1039/c6bm00270f.

169. Kaur G, Pandey OP, Singh K, et al. A review of bioactive glasses: Their structure, properties, fabrication and apatite formation. J Biomed Mater Res A. 2014;102(1):254-274 doi: 10.1002/jbm.a.34690.

170. Galarraga-Vinueza ME, Mesquita-Guimarães J, Magini RS, et al. Anti-biofilm properties of bioactive glasses embedding organic active compounds. J Biomed Mater Res A. 2016. doi: 10.1002/jbm.a.35934.

171. Lendeckel S, Jodicke A, Christophis P, et al. Autologous stem cells (adipose) and fibrin glue used to treat widespread traumatic calvarial defects: case report. J Craniomaxillofac Surg 2004, 32: 370-373.

172. Mesimaki K, Lindroos B, Tornwall J, et al. Novel maxillary reconstruction with ectopic bone formation by GMP adipose stem cells. Int J Oral Maxillofac Surg 2009, 38: 201-209.

173. Thesleff T, Lehtimaki K, Niskakangas T, et al. Cranioplasty with adipose-derived stem cells and biomaterial: a novel method for cranial reconstruction. Neurosurgery 2011, 68: 1535-1540.

174. Sandor GK, Tuovinen VJ, Wolff J, et al. Adipose stem cell tissue-engineered construct used to treat large anterior mandibular defect: a case report and review of the clinical application of good manufacturing practice-level adipose stem cells for bone regeneration. J Oral Maxillofac Surg 2013, 71: 938-950.

175. Sandor GK, Numminen J, Wolff J, et al. Adipose stem cells used to reconstruct 13 cases with cranio-maxillofacial hard-tissue defects. Stem Cells Transl Med. 2014 Apr;3(4):530-40.

176. Pak J, Lee JH, Jeon JH, et al. Complete resolution of avascular necrosis of the human femoral head treated with adipose tissue-derived stem cells and platelet-rich plasma. J Int Med Res. 2014 Dec;42(6):1353-62.

177. Castillo-Cardiel G, López-Echaury AC, Saucedo-Ortiz JA, et al. Bone regeneration in mandibular fractures after the application of autologous mesenchymal stem cells, a randomized clinical trial. Dent Traumatol. 2016 Aug 11.

178. Dufrane D, Docquier PL, Delloye C, et al. Scaffold-free Three-dimensional Graft From Autologous Adipose-derived Stem Cells for Large Bone Defect Reconstruction: Clinical Proof of Concept. Medicine (Baltimore). 2015 Dec;94(50):e2220.

179. Prins HJ, Schulten EA, Ten Bruggenkate CM, et al. Bone Regeneration Using the Freshly Isolated Autologous Stromal Vascular Fraction of Adipose Tissue in Combination With Calcium Phosphate Ceramics. Stem Cells Transl Med. 2016 Oct;5(10):1362-1374.

180. Gimble JM, Guilak F, Bunnell BA: Clinical and preclinical translation of cell-based therapies using adipose tissue-derived cells. Stem Cell Res Ther 2010, 1: 19.

181. Gonzalez-Garza MT, Cruz-Vega DE. Regenerative capacity of autologous stem cell transplantation in elderly: a report of biomedical outcomes. Regen Med. 2017;12(2):169-178.

182. Pak J, Chang JJ, Lee JH, et al. Safety reporting on implantation of autologous adipose tissuederived stem cells with platelet-rich plasma into human articular joints. BMC Musculoskelet Disord. 2013;14,337. 
183. Li F, Zhou C, Xu L, et al. Effect of Stem Cell Therapy on Bone Mineral Density: A MetaAnalysis of Preclinical Studies in Animal Models of Osteoporosis. PLoS One. 2016;11(2):e0149400. doi: 10.1371/journal.pone.0149400.

184. Ye X, Zhang P, Xue S, et al. Adipose-derived stem cells alleviate osteoporosis by enhancing osteogenesis and inhibiting adipogenesis in a rabbit model. Cytotherapy. 2014;16(12):1643-55. doi: 10.1016/j.jcyt.2014.07.009.

185. Liu HY, Chiou JF, Wu AT, et al. The effect of diminished osteogenic signals on reduced osteoporosis recovery in aged mice and the potential therapeutic use of adipose-derived stem cells. Biomaterials. 2012;33(26):6105-12.

186. Akbar MA, Lu Y, Elshikha AS, et al. Transplantation of Adipose Tissue-Derived Mesenchymal Stem Cell (ATMSC) Expressing Alpha-1 Antitrypsin Reduces Bone Loss in Ovariectomized Osteoporosis Mice. Hum Gene Ther. 2017;28(2):179-189. doi: 10.1089/hum.2016.069.

187. Wang L, Huang C, Li Q, et al. Osteogenic differentiation potential of adipose-derived stem cells from ovariectomized mice. Cell Prolif. 2017;50(2). doi: 10.1111/cpr.12328.

188. Pei M, Li J, McConda DB, et al. A comparison of tissue engineering based repair of calvarial defects using adipose stem cells from normal and osteoporotic rats. Bone. 2015;78:1-10. doi: 10.1016/j.bone.2015.04.040.

189. Liu H, Li W, Liu Y, et al. Co-administration of aspirin and allogeneic adipose-derived stromal cells attenuates bone loss in ovariectomized rats through the anti-inflammatory and chemotactic abilities of aspirin. Stem Cell Res Ther. 2015;6:200. doi: 10.1186/s13287-015-0195-x. 